\title{
Examining Relationship and Differences between Student Teachers' First Supervision and Second Supervision Scores
}

\author{
Peter Agbadobi Uloku Ossai \\ Department of Guidance and Counselling, \\ Measurement and Evaluation, \\ Delta State University, Abraka, Nigeria
}

DOI: https://doi.org/10.36941/jesr-2020-0o69

\begin{abstract}
This study examined the relationship and differences between students' teaching practice scores in the first and second supervisions. The aim of the study was to find out whether students' performances in the first supervision could predict performance in the second supervision. To direct the study, two research questions and two null hypotheses were used. An ex-post facto design was employed in the study. The population for the study consisted of 95300 students from the department of Guidance and Counselling, Delta State University, Abraka for 2016/17 session. A sample of 82 students was drawn from 300 level through purposive sampling technique. The two sets of teaching practice scores for 2016/17 session were used in the study. The research questions were answered through the use of co-efficient of determination and mean while the null hypotheses were tested at .o5 level of significance using Pearson's $r$ and independent samples t-test. The data analysis revealed that the two sets of teaching practice scores were positively related; however there was no significant relationship between the scores from the first and second supervisions. It was also found that the two sets of scores did not differ significantly. The weak relationship or difference between the two sets scores from the two supervisions were attributed to students not heeding the supervisors' instructions in the first supervision. Further studies on relationship and differences between students' teaching practice scores should be done with larger samples from other departments and other institutions in the country.
\end{abstract}

Keywords: Relationship, between, students, teaching, practice, scores

\section{Introduction}

It is often believed that correct practice makes perfect. In other words, perfection cannot be achieved without persistent practice. This is true in all fields of human endeavour, including teaching. The need for practice was emphasized by Akinlaye (2003) who said that "since we learn to do things by doing the things repeatedly, and we learn to teach by teaching and mastering the art (methods) of teaching", (p. 116). This author asserted that teachers are made by training, not born.

Practice by teachers is usually done through teaching practice. In Delta State University, Abraka, Teaching Practice is a core course taken in 300 level and 400 level in the Faculty of Education. It attracts three units. The cardinal aim is to expose student-teachers to practical experience. More often than not, some students complain of contradicting comments and scores from supervisors. It is believed by some students that scores provided by supervisors are subjective. It is against this backdrop that this study was conducted to find out the relationship and differences between the two sets of scores awarded to students in their teaching practice exercise. 
Stone and Morris (2002) viewed teaching practice as a practical teaching activity by which the student-teachers are given an opportunity in actual school situation to demonstrate and improve training in pedagogical skill over a period of time. This definition is similar to that given by the National Teachers' Institute (NTI 1999). The author defined teaching practice as the opportunity given to student-teachers to gain practical classroom experience under expert supervision.

Okujagu and Osah-Ogulu (2002) noted that teaching practice exercise is geared towards helping student-teachers become perfect in their professional skills and making them (traineeteachers) creative in problem-solving. The assertion of Aspden (2017) concerning teaching practice is similar to this. According to the author, teaching practice exercise determines students' standards for graduation and readiness to teach.

It takes only an effective teacher to undertake the task of teaching. Mwajim (2015) noted some of the characteristics of an effective teacher as caring about the learner, listening to the concerns of the learner, being self-motivated and self disciplined, knowing the strengths and weaknesses of the learners and looking into the individual needs of every learner.

Students' disposition to teaching practice and teaching practice challenges may affect traineeteachers' performance in teaching practice exercise. Uzoeshi and Asuru (2004) conducted a study on "Attitude of Rivers State College of Education Students towards Teaching Practice". The study involved 200 students consisting of 74 males and 126 females as well as 110 BED students and 90 NCE students. The analysis of the study revealed that sex and programme of study had no significant influence on students' attitude towards teaching practice, but a significant difference existed with respect to school of study and age of students.

Studies on teaching practicum assessment were conducted by Haigh and Tuck (1999) as well as Sedumedi and Mundalamo (2014). Haigh and Tuck (1999) assessed the performance of student teachers in practicum using 150 student teachers in a one-year diploma course in a college of education in New Zealand. The aim of the study was to examine the difference in the assessments done by the school-based supervisors and the visiting lecturers. Data analysis showed that there were variations in the assessments. There were also significant differences in the mean ratings of the two supervisors. Besides, the visiting lecturers were harder in assessment than the school-based supervisors.

Similarly, Sedumedi and Mundalamo (2014) focused on school mentors' assessment of science student teachers involved in teaching practice. Fifty three mentors were used in the study. Mentors' comments and marks were collated in line with the specified variables. Data analysis showed that the comments and allocation of marks by mentors' followed the same pattern.

Nwadiani (1999) reported that problems confronting trainee-teachers in their practice centre on increasing cost. Other challenges associated with students' teaching practice were reported in a study done by Muwonye and SSenyonga in 2015. This study was on "Factors and Challenges Affecting Performance of Student-teachers during their Practicum. The sample consisted of five hundred and sixty-seven (567) second and third year student-teachers doing their teaching practice from 2012 and 2014. Students undergoing their B.Sc Ed. Programme in the Department of Educational Foundations and Psychology at Mbarara University, Uganda were used in the study. Questionnaire and studentteachers' scores in the practice exercise were used in the study. The data analyzed showed that student-teachers' challenges were:

(i) poor social support from school administrators and supervisors from the university

(ii) too many students (large class) in some schools,

(iii) poor allocation of teaching workload

(iv) being unjustly re-posted to other schools and

(v) contradicting comments from supervisors. The need for improvement on the mode of supervision by the lecturers and proper mentorship of the practicum exercise was recommended.

Aspden (2017) noted that there are no easy solutions to the challenges of teaching practicum assessment. The author held that approaches which best reduce subjectivity in practicum assessment 
are advisable.

\section{Purpose of the Study}

The general purpose of this study was to determine the relationship and differences between the two sets of scores awarded to student-teachers in their teaching practice exercise.

\section{Statement of the Problem}

Students take three-unit courses very seriously. Teaching practice is a core course that attracts three units.

It is believed by some students that any score below " $\mathrm{C}$ " is punitive. It is also alleged that teaching practice scores are subjective. The problem of this study, therefore, is to find out the extent of relationship or differences between the two sets of scores obtained by students in their teaching practice exercise.

Two research questions and two hypotheses directed the study.

\section{Research Questions}

(i) What is the extent of relationship between students' teaching practice scores obtained from the first and second supervisions?

(ii) What are the mean scores of students' teaching practice scores in the first and second supervisions?

\section{Hypotheses}

(i) There is no significant relationship between students' teaching practice scores obtained from the first and second supervisions.

(ii) There is no significant difference between students' teaching practice scores obtained from the first and second supervisions

\section{Methodology}

An ex-post facto correlational design was used in the study involving a population of ninety-five 300 level students from the department Guidance and Counselling in Delta State University, Abraka, Nigeria. The students were drawn from the $2016 / 2017$ session. The purposive sampling technique was used to draw a sample size of 82 students from the total population. A specially prepared instrument by the teaching practice committee in the faculty of education was used by lecturers (supervisors) to score students who participated in the $2016 / 2017$ session for 300 level and 400 level. The instrument was deemed to have satisfied the psychometric properties of validity and reliability. While the research questions were answered using co-efficient of determination and mean, the two null hypotheses were tested at 05 level of significance using the product moment correlation statistics and the independent samples t-test.

\section{Data Analysis and Results}

7.1 Research question 1: What is the extent of relationship between students' teaching practice scores obtained from the first and second supervisions? 
Table 1: Showing the Product Moment correlation analysis of students' teaching practice scores obtained from the first and second supervisions.

\begin{tabular}{|l|c|c|c|c|c|}
\hline Variables & $\mathrm{n}$ & $\mathrm{r}$ & $\mathrm{r}^{2}$ & $\mathrm{r}^{2}$ & Remarks \\
\hline First supervision & 82 & .125 & .016 & 2 & small positive relationship \\
Second supervision & 82 & 25 \\
\hline
\end{tabular}

Table 1 shows that $\mathrm{r}$ is 0.125 while $\mathrm{r}^{2}$ is 0.016 ; thus, the co-efficient of determination is $2 \%$. That is, students' teaching practice scores in the second supervision were influenced by $2 \%$ of the scores in the first supervision.

\subsection{Research question 2: What are the mean scores of the first and second supervision}

\begin{tabular}{|l|ccc|}
\hline Variable & N & Mean & Mean difference \\
\hline First supervision & 82 & 62.6 & \multirow{2}{*}{0.6} \\
Second supervision & 82 & 63.2 & \\
\hline
\end{tabular}

Table 2 shows that the mean scores for the first and second supervision are 62.6 and 63.2 respectively. The mean difference is o.6. in favour of the second supervision.

\section{Hypotheses Testing}

8.1 Hypothesis one: There is no significant relationship between students' teaching practice scores in the first and second supervisions.

Table 3: Showing the Product Moment Correlation analysis of first and second supervisions.

\begin{tabular}{l|c|c|c|c|c}
\hline Variables & $\mathrm{N}$ & $\mathrm{r}$ & $\mathrm{df}$ & sig. & Remarks \\
\hline First supervision & 82 & 0.125 & 162 & .263 & not significant \\
Second supervision & 82 & 162 & \\
\hline
\end{tabular}

From Table 3, $\mathrm{r}$ is 0.125 ; at $\mathrm{df}=162, \mathrm{p}$-value is 0.263 . Since $\mathrm{p}$-value is greater than the value of .05, the null hypothesis is accepted. This means that there is no significant relationship between students' teaching practice scores in the first and second supervisions.

8.2 Hypothesis two: There is no significant difference in the mean scores of students' first and second teaching practice supervisions.

Table 4: Showing the t-test analysis of students' first and second supervision scores

\begin{tabular}{l|c|c|c|c|c}
\hline Variables & $\mathrm{N}$ & Mean & $\mathrm{df}$ & sig. & Remarks \\
\hline First supervision & 82 & 62.6 & \multirow{2}{*}{162} & .568 & not significant \\
Second supervision & 82 & 63.3 & & .56 & \\
\hline
\end{tabular}

From Table 4, mean scores for the first and second supervisions are 62.6 and 63.2, respectively. At $\mathrm{df}=162 \mathrm{p}$-value of .568 is greater than .05 alpha level of significance. Hence, the null hypothesis is retained. This implies that there is no significant difference in the mean scores of students' first and second supervisions. 


\section{Discussion of Findings}

Answers to research questions 1 and 2 indicated that the relationship between students' scores in their first and second supervisions was positive. This is a small relationship. Only $2 \%$ of the scores in the second supervision can be attributed to students' performances in the first supervision. Using interpretation of Cohen (1988), the effect is small.

A further examination of the answer to the research questions led to the finding that there is no significant relationship between students' teaching practice scores obtained from the first and second supervisions. This finding is in line with Muwonye and Ssnyonga (2015) who reported in their study that contradicting comments on student-teachers' teaching practice behaviours were made by different supervisions. It can also be inferred from the finding that students' scores in the second supervision cannot be predicted from performance in the first supervision.

Research question two showed that students' mean scores in the second supervision was o.6 units higher than the mean scores obtained in the first supervision. The difference is marginal. The hypothesis test of the two sets of supervision scores showed that the mean scores from both supervisions did not differ significantly.

The finding from this study supports the earlier finding reported by Ossai (2017). Ossai studied relationship between students' scores from practicum I and practicum II and observed that there was no significant relationship between the two sets of scores. The study also showed that students' mean scores in the second practicum improved slightly compared to the first exercise. The study also agrees with Haigh and Tuck (1999) who observed significant differences in the assessments of the schoolbased supervisors and the visiting lecturer. However, the result is contrary to the earlier finding by Sedumedi and Mundalamo (2014) who reported consistency in the comments and scores from the mentors that assessed some science students who participated in a practicum exercise.

This finding also suggests that student-teachers must have demonstrated the fact that they were exposed to the same practicum instructions. Hence, there was no significant difference in the two exercises. This apparent attitude is in line with the works of Uzoeshi and Asuru (2004). Uzoeshi and Asuru observed that sex and programme of study had no significant influence on students' attitude towards teaching practice.

It can be inferred from this present study that the student-teachers must have been nervous in the first round of supervision. Mansor and Yusoff (2013) reported in their study concerning traineecounsellors that the subjects showed signs of nervousness at the beginning of their practicum and internship.

\section{Conclusion}

The two sets of scores from students' first and second supervisions had a small positive relationship. The mean scores from the first supervision is slightly below that of the second supervision.

Even though the findings appear to demonstrate the fact the students must have been exposed to similar conditions on the two occasions, it can be inferred that they (the students) did not pay heed to the instructions given in the first supervision. Otherwise, performances in the second round would have improved greatly. The small positive relationship implies that scores from the first supervision cannot truly predict scores from the second supervision.

Another possible trend that can be deduced from the findings is inconsistency in scores. This calls for more studies involving larger samples.

\section{Recommendations}

It was recommended that further studies on relationship and differences between student-teachers' teaching practice scores be extended to:

(i) more departments; 
(ii) part-time programme and

(iii) other universities in the country.

\section{References}

Akinlaye, F.A. (2003) Fundamentals of Social Studies. Lagos: Punmark Nigeria Limited.

Aspden, K.M (2017). The complexity of practicum assessment in teacher education: an examination of four New Zealand case studies. Australian Journal of Teacher Education, 42(12), 128-143.

Haigh, M. \& Tuck, B. (1999). Assessing student teachers' performance in

Practicum. Paper presented at the AARE annual conference. Melbourne. https://www.aare.edu.au/data/publications/1999/tuc99118.pdf

Mansor , N \& Yusoff, W.M. (2013). Feelings and experiences of counselling Practicum students and implications for counselling supervision. Journal of Educational and Social Research, 3(7), 731- 736.

Muwonye, C.M. \& Sssenyonga, J. (2015). Factors and Challenges Affecting Performance of Student-teachers during their Practicum. Journal of Education, Psychology and Social Sciences, vol. 3, p. 44-49

Mwaiem, A.U. (2015). Ethics of Teaching Profession in Nigeria. Jattu-Uzairu. Stirling-Hordan Publishers Ltd.

National Teachers' Institute, NTI (1999). Key Points and Essential Notes in Education. Principles and Practice. Benin City: Favourite Printers.

Nwanekezi, A.U.; Okoli, N.J. \& Mezieobi, S.A. (2011). Attitude of Student-teachers Towards Teaching Practice. Journal of Emerging Trends in Educational Research and Policy Studies, 2(1), 41-46

Ossai, P.A.U. (2017). Relationship between students' scores in practicum I and Practicum II. Delsu Journal of Educational Research and Development, 16(1), 55-62 .

Sedumedi, T.D.T. \& Mundalamo, F.J. (2014). School mentors' assessment of science student teachers during teaching practicum. Mediterranean Journal of Social Sciences, 5(20), 1611-1620.

Stone, E. \& Morris, S. (2002). Teaching Practice Problems and Prospects. London: Methuem and Co. Ltd.

Uzoeshi, K.C. \& Asuru, V.A. (2004). Attitude of Rivers State College of Education Students Towards Teaching Practice. In O.A. Afemikfre \& J.G. 